\title{
Erratum to: Free associate norms for 139 European Portuguese words for children from different age groups
}

\author{
Montserrat Comesaña $\cdot$ Isabel Fraga $\cdot$ \\ Ana Júlia Moreira • Carla Sofia Frade • Ana Paula Soares
}

Published online: 31 January 2014

(C) Psychonomic Society, Inc. 2014

Erratum to: Behav Res

DOI 10.3758/s13428-013-0388-0

The first paragraph is a direct quote from Nelson, McEvoy, \& Schreiber, 1998, and as such should be set off by quotation marks.

The online version of the original article can be found at http:// dx.doi.org/10.3758/s13428-013-0388-0.

M. Comesaña $(\bowtie) \cdot$ A. J. Moreira $\cdot$ A. P. Soares

Human Cognition Lab, CIPsi, School of Psychology, University of

Minho, Campus de Gualtar, 4710-057 Braga, Portugal

e-mail: mvila@psi.uminho.pt

M. Comesaña $\cdot$ I. Fraga

Cognitive Processes \& Behaviour Research Group, University of

Santiago de Compostela, Santiago de Compostela, Spain

C. S. Frade

Faculty of Psychology, University of Lisbon, Lisbon, Portugal 